\title{
Salt acclimation processes in wheat
}

Tibor Janda ${ }^{1 *}$, Éva Darko ${ }^{1}$, Sami Shehata ${ }^{2}$, Viktória Kovács ${ }^{1}$, Magda Pá1 ${ }^{1}$, Gabriella Szalai ${ }^{1}$

${ }^{1}$ Agricultural Institute, Centre for Agricultural Research, Hungarian Academy of Sciences, H2462 Martonvásár, POB 19.

${ }^{2}$ National Research Centre, El Buhouth St., Dokki, Cairo, Egypt

*corresponding author:

Tibor Janda

Tel.: +36 22569 509, fax: +3622569576

E-mail addresses:

janda.tibor@agrar.mta.hu (T. Janda), darko.eva@agrar.mta.hu (É. Darko), $\underline{\text { sami.shehata@gmail.com }}$ (S. Shehata), kovacs.viktoria@agrar.mta.hu (V. Kovács), pal.magda@agrar.mta.hu (M. Pál), szalai.gabriella@agrar.mta.hu (G. Szalai)

\section{ABSTRACT}

Young wheat plants (Triticum aestivum L. cv. Mv Béres) were exposed to 0 or $25 \mathrm{mM} \mathrm{NaCl}$ for 11 days (salt acclimation). Thereafter the plants were irrigated with $500 \mathrm{mM} \mathrm{NaCl}$ for 5 days (salt stress). Irrigating the plants with a low concentration of $\mathrm{NaCl}$ successfully led to a reduction in chlorotic symptoms and in the impairment of the photosynthetic processes when the plants were exposed to subsequent high-dose salt treatment. After exposure to a high concentration of $\mathrm{NaCl}$ there was no difference in leaf $\mathrm{Na}$ content between the salt-acclimated and non-acclimated plants, indicating that salt acclimation did not significantly modify $\mathrm{Na}$ transport to the shoots. While the polyamine level was lower in salt-treated plants than in the 
control, salt acclimation led to increased osmotic potential in the leaves. Similarly, the activities of certain antioxidant enzymes, namely glutathione reductase, catalase and ascorbate peroxidase, were significantly higher in salt-acclimated plants. The results also suggest that while SOS1, SOS2 or NHX2 do not play a decisive role in the salt acclimation processes in young wheat plants; another stress-related gene, WALI6, may contribute to the success of the salt acclimation processes. The present study suggested that the responses of wheat plants to acclimation with low level of salt and to treatment with high doses of salt may be fundamentally different.

\section{Highlights:}

- Salt acclimation protects wheat plants against high salinity

- Salt acclimation did not affect the Na transport to the leaves in wheat plants

- Responses to salt acclimation differs from high salt concentration

- Osmotic adjustment and antioxidant system are important factors in salt acclimation

- WALI6 may play role in salt acclimation process

Keywords: acclimation; gene expression; oxidative stress; salinity; Triticum aestivum L.

Abbreviations: APX, ascorbate peroxidase; $\mathrm{C}_{\mathrm{i}}$, intracellular $\mathrm{CO}_{2}$ concentration; $\mathrm{E}$, transpiration; $F_{v}$, variable fluorescence at dark adapted state; $F_{m}$ maximum fluorescence at dark adapted state; G-POD, guaiacol peroxidase; GR, glutathione reductase; $\mathrm{g}_{\mathrm{s}}$, stomatal conductance; NPQ, non-photochemical quenching; Pn, net photosynthesis; PPFD, photosynthetic photon flux density; PSII, Photosystem II; ROS, reactive oxygen species; WUE, water use efficiency. 


\section{Introduction}

High salinity is one of the most widespread abiotic stress factors in agriculture, causing problems in plant production both on naturally saline soils and on irrigated lands with unsuitable water management or exposure to high evaporation. Depending on the level of the stress and the stage of plant development, high salinity may induce various physiological malfunctions (Hossain et al., 2015; Kranner and Seal, 2013). Osmotic stress, as a primary reaction triggered by relatively moderate salinity levels, decreases soil water potential, reduces water uptake and may cause cell dehydration, stomatal closure and a decline in photosynthetic activity, leading to a limited growth rate. At high salinity ionic stress may also occur when ions are taken up by plants at an above-optimum concentration. Specific ionic stresses lead to a disruption of the integrity and selectivity of the root plasma membrane, the homeostasis of essential ions, and numerous metabolic activities.

Plants have developed several survival mechanisms to reduce the damaging effects of high salinity. These processes include the selection or exclusion of undesirable ions, the control of ion uptake by the roots and their transport into the leaves, the compartmentalization of ions at the cellular and whole-plant levels, the synthesis of compatible solutes, the adjustment of photosynthetic processes, alterations in membrane structure, the induction of antioxidant enzymes to reduce the level of oxidative stress, and the reprogramming of plant hormone synthesis (reviewed by Parida and Das, 2005). An important component of salt tolerance in plants is the minimising of $\mathrm{Na}^{+}$uptake by the roots. The salt-overly-sensitive (SOS) signal-transduction pathway is important for ion homeostasis and salt tolerance in plants. In this system a salt-induced transient increase in the $\mathrm{Ca}^{2+}$ level is sensed by the calcium-binding protein SOS3, which activates the serine/threonine protein kinase SOS2. The SOS2/SOS3 complex activates the plasma membrane $\mathrm{Na}^{+} / \mathrm{H}^{+}$exchanger protein $\mathrm{SOS} 1$ 
(Hasegawa et al., 2000, Qiu et al., 2002). In Arabidopsis 8 isoforms of $\mathrm{Na}^{+} / \mathrm{H}^{+}$antiporter genes (NHX homologues) have been described (Bassil and Blumwald 2014). AtNHX1 and AtNHX2 are highly expressed in many tissues, while AtNHX3 and AtNHX4 are exclusively expressed in flowers and roots (Aharon et al., 2003, Yokoi et al., 2002). Recent results also suggested that $\mathrm{NHX} 1$ and $\mathrm{NHX} 2$ are vacuolar $\mathrm{K}^{+} / \mathrm{H}^{+}$exchangers that control vacuolar $\mathrm{pH}$ and $\mathrm{K}+$ homeostasis, they are essential for active $\mathrm{K}^{+}$uptake at the tonoplast, osmotic adjustment and turgor regulation, and that they play a unique role in stomatal function (Bassil et al., 2011, Barragan et al., 2012).

The exposure of plants to a moderate level of a stressor may induce protective mechanisms enabling the plants to tolerate a subsequent drastic stress factor (Janda et al., 2014). Pre-treatment of plants with a low concentration of $\mathrm{NaCl}$ has also been reported as an effective process to induce a higher level of salt tolerance. This phenomenon is usually referred to as salt acclimation or acquired salinity tolerance (Amzallag et al., 1990; Umezawa et al., 2000; Pandolfi et al., 2012).

Although a large body of data has been collected on the mechanisms of salt tolerance in various plants species, much less is known about the physiological and molecular background of salt acclimation processes, especially in monocot cereals. In the present work it was demonstrated that the treatment of young wheat plants with a low concentration of $\mathrm{NaCl}$ may increase their tolerance to a subsequent high-dose salt stress. Certain key mechanisms responsible for the improved salt tolerance induced by salt acclimation were also revealed by comparing the effects of acclimation with a low salt level and the responses of wheat plants to a high dose of salt.

\section{Materials and methods}




\subsection{Plant material and growth conditions}

Wheat plants (Triticum aestivum L. var. Mv Béres) were grown under controlled growth conditions in a Conviron PGR-15 plant growth chamber (Controlled Environments Ltd, Winnipeg, Canada) in the phytotron of the Agricultural Institute, Centre for Agricultural Research, Hungarian Academy of Sciences, Martonvásár at $22 / 20{ }^{\circ} \mathrm{C}$ day/night temperature, $75 \%$ relative humidity and approx. $320 \mu \mathrm{mol} \mathrm{m} \mathrm{m}^{-2} \mathrm{~s}^{-1}$ photosynthetic photon flux density (PPFD), in $12 \mathrm{~cm}$ diameter pots filled with loamy soil and irrigated occasionally with tap water. After a week half the pots were irrigated with $25 \mathrm{mM} \mathrm{NaCl}$ solution dissolved in tap water for 11 days (salt acclimation). After the acclimation period, the plants were irrigated with $500 \mathrm{mM} \mathrm{NaCl}$ (salt stress).

For biochemical and physiological analyses the middle parts of the youngest fully expanded leaves were used. Samples were collected after 1 day of high salinity for polyamine, antioxidant enzyme, gene expression and after 5 days for pigment and $\mathrm{Na}$ content measurements and for the osmotic potential determinations. Gas exchange and chlorophyll fluorescence induction measurements were also carried out on intact leaves after 1 or 5 days after treatment with $500 \mathrm{mM} \mathrm{NaCl}$, respectively.

\subsection{Measurement of photosynthetic pigments}

The chlorophyll ( $a$ and $b$ ) and carotenoid contents of the leaves were determined spectrophotometrically after extracting the leaf segments (100 $\mathrm{mg}$ per sample) in $80 \%$ acetone, according to the method of Lichtenthaler (1987).

\subsection{Gas exchange measurements}


Gas exchange analysis was performed on intact leaves with a Ciras 2 Portable Photosynthesis System (Amesbury, USA) using a narrow leaf area $\left(2.5 \mathrm{~cm}^{2}\right)$ chamber. The measurements were performed 1 day after salt stress treatment. The parameters $\mathrm{CO}_{2}$ assimilation rate $(\mathrm{Pn})$, stomatal conductance $\left(\mathrm{g}_{\mathrm{s}}\right)$, intracellular $\mathrm{CO}_{2}$ concentration $\left(\mathrm{C}_{\mathrm{i}}\right)$ and transpiration (E) were determined at the steady-state level of photosynthesis. The reference level of $\mathrm{CO}_{2}$ was $380 \mu \mathrm{L} \mathrm{L}^{-1}$ and the light intensity was $250 \mu \mathrm{mol} \mathrm{m}^{-2} \mathrm{~s}^{-1}$.

\subsection{Fluorescence induction measurements}

Chlorophyll $a$ fluorescence quenching analysis was carried out using a pulse amplitude modulated fluorometer (Imaging-PAM M-Series fluorometer; Walz, Effeltrich, Germany) on detached leaves of wheat plants with or without salt stress $(500 \mathrm{mM} \mathrm{NaCl})$ for 5 days. The plants were previously dark-adapted for 20 minutes, after which the $F_{v} / F_{m}$ parameter was determined using a $0.8 \mathrm{~s}$ saturation pulse $\left(\mathrm{PPFD}=3000 \mu \mathrm{mol} \mathrm{m} \mathrm{m}^{-2} \mathrm{~s}^{-1}\right)$ provided by a LEDArray Illumination Unit IMAG-MAX/L $(\lambda=450 \mathrm{~nm})$. Photosynthesis was then activated using $230 \mu \mathrm{mol} \mathrm{m} \mathrm{m}^{-2} \mathrm{~s}^{-1}$ actinic light intensity for $15 \mathrm{~min}$ and the quenching analysis was performed using a $30 \mathrm{~s}$ saturation pulse frequency. The quenching parameters were determined under steady state conditions according to the nomenclature described by Klughammer and Schreiber (2008).

\subsection{Determination of Na content}

The $\mathrm{Na}$ content in the leaves was determined from air-dried samples (approx. $0.5 \mathrm{~g}$ of each sample) using the inductively coupled plasma-atomic emission spectrometry method 
(ICP-AES, Jobin-Yvon Ultima 2 sequential instrument) after microwave Teflon bomb digestion with cc. $\mathrm{HNO}_{3}+\mathrm{HCl}$ (Anton et al., 2012).

\subsection{Osmotic potential measurements}

The osmolarity of the leaf sap from control, salt-acclimated and salt-stressed leaves with and without acclimation was measured using a cryoscopic osmometer, Osmomat 3000 (Gonotech GmbH, Berlin, Germany) and the osmotic potential values $\left(\Psi_{\pi}\right)$ were calculated as described by Bajji et al. (2001). Samples for analysis were collected after 5 days of salt stress.

\subsection{Polyamine determination}

Polyamine analysis was carried out from leaf segments as described by Németh et al. (2002). Two hundred milligrams of leaves were homogenized with $1 \mathrm{ml} 0.2 \mathrm{M}$ ice-cold perchloric acid and were allowed to stand for $20 \mathrm{~min}$ on ice. The extract was centrifuged at 10 $000 \mathrm{~g}$ for $20 \mathrm{~min}$ and the supernatant was used. The polyamines were analysed as dansylated derivatives via HPLC using a W2690 separation module and a W474 scanning fluorescence detector with excitation at $340 \mathrm{~nm}$ and emission at $515 \mathrm{~nm}$ (Waters, Milford, MA, USA). Conjugated and bound forms of PAs were measured after 1 hour of acid hydrolysis at $96{ }^{\circ} \mathrm{C}$.

\subsection{Measurements of antioxidant activities}

For the analysis of antioxidant enzyme activity, $0.5 \mathrm{~g}$ tissue was homogenized in $2.5 \mathrm{ml}$ ice-cold Tris-HCl buffer (0.5 M, pH 7.5) containing $3 \mathrm{mM} \mathrm{MgCl}_{2}$ and $1 \mathrm{mM}$ EDTA. 
The glutathione reductase (GR; EC 1.6.4.2.) activity was determined at $412 \mathrm{~nm}$ according to Smith et al. (1988). The reaction mixture contained $75 \mathrm{mM}$ Na-phosphate buffer (pH 7.5), $0.15 \mathrm{mM}$ diethylenetriamine-pentaacetic acid, $0.75 \mathrm{mM} \mathrm{5,5'-dithiobis(2-nitrobenzoic} \mathrm{acid),}$ $0.1 \mathrm{mM}$ NADPH, $0.5 \mathrm{mM}$ oxidized glutathione and $50 \mu \mathrm{l}$ plant extract in a total volume of 1 ml. The catalase (CAT; EC 1.11.1.6.) activity of the extract was measured spectrophotometrically by monitoring the decrease in absorbance at $240 \mathrm{~nm}$ (Janda et al. 1999). The reaction mixture contained $0.44 \mathrm{M}$ Tris- $\mathrm{HCl}$ buffer ( $\mathrm{pH} 7.4), 0.0375 \% \mathrm{H}_{2} \mathrm{O}_{2}$ and enzyme extract. The ascorbate peroxidase (APX; EC 1.11.1.11.) activity was determined in the presence of $0.2 \mathrm{M}$ Tris- $\mathrm{HCl}$ buffer $(\mathrm{pH} 7.8)$ and $5.625 \mathrm{mM}$ ascorbic acid. The reaction was started with $0.042 \% \mathrm{H}_{2} \mathrm{O}_{2}$. The decrease in absorbance at $290 \mathrm{~nm}$ was monitored as described by Janda et al. (1999). The guaiacol peroxidase (G-POD; EC 1.11.1.7.) activity was measured at $470 \mathrm{~nm}$ as described by Ádám et al. (1995). The reaction mixture consisted of 88 $\mathrm{mM} \mathrm{Na}$-acetate buffer ( $\mathrm{pH} 5.5$ ), $0.88 \mathrm{mM}$ guaiacol, $0.0375 \% \mathrm{H}_{2} \mathrm{O}_{2}$ and enzyme extract. The enzyme activities were determined photometrically with a UV-visible recording spectrophotometer (UV-VIS 160A, Shimadzu Corp. Kyoto, Japan).

\subsection{Total RNA isolation and cDNA synthesis}

Total RNA was isolated from the leaf samples using TRI-Reagent (Zymo Research, USA), treated with DNase I and cleaned with a Direct-zol ${ }^{\mathrm{TM}}$ MiniPrep Kit (Zymo Research, USA) according to the manufacturer's instructions. Isolated RNA concentrations were measured photometrically (NanoDrop ND-1000 UV-Vis spectrophotometer, NanoDrop Technologies, Wilmington, DE, USA). First strand cDNA synthesis was performed on $1 \mu \mathrm{g}$ total RNA, using M-MLV Reverse Transcriptase (Promega, 200 U), dNTP (Thermo Scientific, $10 \mathrm{mM}$ ) and Oligo(dT)18 primers (Thermo Scientific, $100 \mu \mathrm{M}$ ) in $25 \mu \mathrm{L}$ in a 
thermocycler (Applied Biosystem, Foster City, CA, USA). Then $75 \mu \mathrm{L}$ sterile Milli-Q water was added to the first strand cDNA samples, which were stored at $-20^{\circ} \mathrm{C}$ until use.

\subsection{Gene expression analysis with $q R T-P C R$}

Quantitative real-time PCR (qRT-PCR) was performed with an Applied Biosystems Fast 7500 instrument using SYBR Green detection chemistry (QuantiFast SYBR Green PCR Kit, Qiagen) and gene-specific primers (Table 1) according to Pál et al (2014). The wheat Ta30797 (TC279294, TC284282) gene was used for the endogenous control. The primers were designed to be specific to the highly conserved domain of known Triticum gene sequences. The relative ratio of threshold cycle $(\mathrm{Ct})$ values between the endogenous control and the specific genes were calculated for each sample.

\subsection{Statistical analysis}

The results were obtained from three independent series of experiments and the data show representative sets of measurements. The results are the means of at least 3-5 measurements and were statistically evaluated using the standard deviation and T-test methods.

\section{Results}

\subsection{Salt acclimation may protect young wheat plants from high salinity levels}

Wheat plants were pre-treated with a low concentration of salt (irrigation with $25 \mathrm{mM}$ $\mathrm{NaCl})$ and then exposed to a high level of salinity $(500 \mathrm{mM} \mathrm{NaCl})$. While treatment with 25 $\mathrm{mM} \mathrm{NaCl}$ caused a slight increase in the chlorophyll content, high salinity substantially 
decreased it. The level of chlorosis after 5 days of salt stress was dramatic in non-acclimated plants; while those previously exposed to a low concentration of $\mathrm{NaCl}$ showed much less pronounced chlorotic symptoms (Fig. 1A). Chlorophyll $a / b$ was also higher in plants pretreated with a low $\mathrm{NaCl}$ concentration. In parallel to the decrease in chlorophyll $(a+b)$ content, the salt stress $(500 \mathrm{mM} \mathrm{NaCl})$ resulted in a reduction in the chlorophyll $a / b$ ratio indicating the greater degradation of chlorophyll $a$ than chlorophyll $b$ especially in case of in non-acclimated plants. Salt acclimation led to a slight, but statistically significant rise in the carotenoid content both with and without salt stress (Fig. 1C). These results indicate that salt acclimation may reduce the stress effects of subsequent high salinity stress in wheat plants.

\subsection{Photosynthetic behaviour after salt acclimation}

In order to characterise the physiological state of plants under salt-acclimated conditions, gas exchange (Table 2) and chlorophyll $a$ fluorescence induction parameters (Table 3) were measured. Salt acclimation with $25 \mathrm{mM} \mathrm{NaCl}$ led to a slight, but statistically significant decrease in Pn, which was probably due to the reduced $g_{s}$ and $E$. There were no significant differences in the level of $\mathrm{C}_{\mathrm{i}}$, the water use efficiency (WUE, calculated as $\mathrm{Pn} / \mathrm{E}$ ) or the chlorophyll $a$ fluorescence induction parameters, namely $\mathrm{F}_{\mathrm{v}} / \mathrm{F}_{\mathrm{m}}$, which represents the maximum quantum efficiency of Photosystem II (PSII), $\Phi_{\mathrm{PSII}}$, the actual quantum efficiency of PSII measured in the light-adapted state and NPQ the non-photochemical quenching, which reflects the rate of thermal energy dissipation (Table 3). These results indicate that salt acclimation mainly affected stomatal closure, and that there was no substantial effect on processes directly related to the photosynthetic electron transport chain.

The $500 \mathrm{mM}$ salt stress caused a complete inhibition of $\mathrm{CO}_{2}$ assimilation processes including stomatal closure and transpiration, making it impossible to differentiate between the 
treatments even after 1 day (data not shown). By contrast, the chlorophyll $a$ fluorescence parameters showed distinct changes. In non-acclimated plants the blocking of $\mathrm{CO}_{2}$ assimilation was accompanied by a decrease in the PSII efficiency as indicated by the lower values of $F_{v} / F_{m}$, quantum efficiency and the elevated level of non-photochemical quenching. These changes were not significant in plants pre-treated with a low concentration of salt (Table 3).

\subsection{Na content}

In order to investigate the effects of salt acclimation on $\mathrm{Na}$ accumulation, the $\mathrm{Na}$ content was measured in the leaves after 5 days of $500 \mathrm{mM}$ salt stress. Irrigation with a low concentration of saline water slightly increased the level of $\mathrm{Na}$ in the leaves, while exposure to a high $\mathrm{NaCl}$ concentration for 5 days drastically increased the $\mathrm{Na}$ level (Fig. 2). The difference in $\mathrm{Na}$ content between acclimated and non-acclimated plants after 5 days of salt stress was not statistically significant, indicating that the reduced uptake and transport of $\mathrm{Na}$ from the root to the shoot is not the main salt acclimation mechanism.

\subsection{Osmotic potential}

As part of the acclimation process plants may modify the osmotic potential of the cells. Irrigating the plants with either low $(25 \mathrm{mM})$ or high $(500 \mathrm{mM}) \mathrm{NaCl}$ increased the osmotic potential in the leaves. Plants previously acclimated with $25 \mathrm{mM}$ salt had higher osmotic potential values after exposure to a high level of salt stress (Fig. 3), suggesting that the improved level of salt tolerance in acclimated plants can be at least partly explained by their better ability to adjust their osmotic pressure. 


\subsection{Polyamines}

Spermidine was the most abundant polyamine species among the major polyamines (namely putrescine, spermidine and spermine) in wheat plants in the present experiment. The levels of the free and conjugated forms, i.e. those, which were connected with small molecules, were in the same range. In general, salt acclimation caused a significant decrease in the total polyamine content, especially in the case of spermidine and spermine. This decrease caused by salt acclimation was statistically significant for free spermidine and spermine in non-stressed plants (without $500 \mathrm{mM} \mathrm{NaCl}$ ) (Fig. 4A). Severe salt stress (500 $\mathrm{mM} \mathrm{NaCl}$ ) did not substantially modify the free polyamine content of the leaves in nonacclimated plants as compared to control plants. Application of severe salt stress to acclimated plants caused a statistically significant decrease all the free major polyamines. A similar tendency was observed for conjugated polyamines (Fig. 4B). In the case of the conjugated forms, only the decreases in spermine and spermidine in non-stressed plants were statistically significant when the effect of the salt acclimation was investigated. Treatment with $500 \mathrm{mM}$ salt significantly reduced the putrescine and spermidine levels in the acclimated plants. (Fig. 4B). Cadaverine, a minor polyamine showed a pattern similar to that found for the most abundant polyamines, having a lower level in salt-acclimated than in non-acclimated plants, while not changing significantly in response to a high $\mathrm{NaCl}$ concentration (data not shown).

3.6. Antioxidant enzymes 
Since a high level of salinity may be accompanied by oxidative stress, the activities of certain antioxidant enzymes, namely GR, catalase, APX and G-POD, were also determined. The GR, catalase and APX activities were found to be influenced by the salt treatments, rising after both salt acclimation and salt stress. G-POD was only slightly induced by a high level of salinity, while salt acclimation caused no significant changes (Fig. 5).

\subsection{Gene expression studies}

Gene expression studies were carried out to clarify the mechanism(s) of salt acclimation processes. In the present experiment the focus was on certain selected genes earlier found to be related to general stress tolerance or to cope directly with high level of salt in plants. Quantitative RT-PCR results showed that while the expression of SOS1 gene was not significantly affected by any type of salt-treatments, the expression level of SOS 2 increased after exposure for $1 \mathrm{~d}$ to $500 \mathrm{mM} \mathrm{NaCl}$. However, this increase was more pronounced in the non-acclimated plants. The $N H X 2$ gene responded similarly to $500 \mathrm{mM} \mathrm{NaCl}$ : its expression level significantly increased in leaves of both non-acclimated and acclimated plants. The expression rate of WALI6, which has been characterised as a stress-responsive gene, showed the highest induction after salt treatment. It has increased even after treatment with low concentration of $\mathrm{NaCl}(25 \mathrm{mM})$, while drastic salt stress further elevated its activity in both non-acclimated and salt-acclimated plants; however, it was still higher in the salt-acclimated plants.

\section{Discussion}

Exposure of plants to low dose of $\mathrm{NaCl}$ may improve their tolerance to salinity stress. This can be achieved by either seed priming, or by direct irrigation of plants prior high dose 
salt stress (Patade et al., 2009; Xie et al., 2011). In the present work in order to determine the effectiveness of salt acclimation young wheat plants were trained with low concentration of $\mathrm{NaCl}$ before irrigation with high salinity and the acclimation mechanisms were investigated. Although especially under field condition rapidly changing salt concentrations in soils rarely occur, the conditions used in the present experiment could clearly demonstrate the effectiveness and general beneficial effects of salt acclimation using moderate salt treatment.

Chlorosis is one of the main symptoms of severe salt stress in plants. In the present work a decrease in the total chlorophyll content of wheat plants was accompanied by a decrease in the chlorophyll $a / b$ ratio, in agreement with studies made in the field, where a greater decrease in chlorophyll $a$ than in chlorophyll $b$ also led to a decrease in chlorophyll $a / b$ under saline conditions (Kiani-Pouya and Rasouli, 1994). The present results also showed that acclimation with a low concentration of $\mathrm{NaCl}$ efficiently reduced the chlorotic symptoms during subsequent high-dose salt stress. The next aim was to explore the physiological and biochemical background of salt acclimation mechanisms in wheat.

Gas exchange and chlorophyll $a$ fluorescence data indicated that salt acclimation were not severely stressful for the plants. Although irrigation with low concentration of saline water slightly reduced the net photosynthesis, it was only due to a reduced stomatal conductivity and not due to damage in the photosynthetic apparatus, as indicated by the chlorophyll fluorescence parameters. However, high salt stress significantly affected the photosynthetic electron transport processes, which included a reduction in the quantum efficiency of PSII and an increase in the non-photochemical quenching indicating the facilitation of the thermal dissipation of excitation energy. The photosynthetic response of non-acclimated wheat plants to high level of salt stress is in line with that expected from the responses of a variety of other stress-sensitive species (Stepien and Johnson, 2009). Exposure of plants to salt-treatment induced stomatal closure resulting limitation on $\mathrm{CO}_{2}$ entry and 
inhibition of $\mathrm{CO}_{2}$ assimilation. However, these changes were not substantial in the saltacclimated plants. Down-regulation of linear electron transport may limit oxidative stress and increased cyclic flow enhances photoprotective energy dissipation. Photoreduction of oxygen can occur in the Mehler reaction at the acceptor side of Photosystem I taking electrons away from the electron transport chain and so tend to protect PSII from photoinhibition. Furthermore, since the cyclic electron flow does not produce any toxic ROS, it may be more important for the long-term regulation of the quantum yield of PSII and NPQ (Makino et al, 2002).

Changes in $\mathrm{Na}^{+}$uptake or transport processes are among the mechanisms which may contribute to better salt tolerance in cereals (Saqib et al., 2011; Darko et al., 2015). In the present experiments, there was no difference in the leaf $\mathrm{Na}$ content of salt-acclimated and non-acclimated plants after exposure to high $\mathrm{NaCl}$, indicating that salt acclimation did not significantly modify $\mathrm{Na}$ transport to the shoots, and suggesting that, under these experimental conditions, protective mechanisms other than altered $\mathrm{Na}$ transport to the leaves must be responsible for the reduced level of damage symptoms in the salt-acclimated plants. The better performance of salt-acclimated plants under high saline conditions was probably at least partly due to the improvement of osmotic adjustment, as demonstrated by the elevated osmotic potential under both control and salt stress conditions (i.e. without or with $500 \mathrm{mM}$ $\mathrm{NaCl}$, respectively). These results are in accordance with earlier findings where comparative analysis revealed that salt-tolerant genotypes are characterised by higher osmotic adjustment ability (Darko et al., 2015).

Polyamines are a group of aliphatic amines that are found in all living cells and appear to be essential for life (Minocha et al., 2014; Tiburcio et al., 2014). Their role in stress protection has been widely studied, including their possible involvement in salinity stress (Do et al., 2014). Due to their cationic nature they are able to interact with negatively charged 
macromolecules in a reversible way, possibly stabilizing their structure, which may be especially important under stress conditions. Their role in stress signalling has also been described (Pál et al., 2015). However, in the present work no polyamine induction was detected in either salt-acclimated or salt-stressed wheat plants. Although polyamines are usually considered to be stress protective compounds, salt acclimation led to a significant decrease in their levels in almost all cases. Furthermore, neither the free nor the conjugated form showed any increase after exposure to a high concentration of salinity for 1 day. These results suggest that in these plants polyamines do not play a direct role in the development of salt tolerance during the salt acclimation period. Salt acclimation induced other physiological processes, which allowed plants to function at lower polyamine levels.

Previous results suggested that salt injury may accelerate the production of ROS, which cause the oxidative degradation of biomolecules, including photosynthetic pigment chlorophylls, proteins and lipids. The antioxidative systems also play an important role in protection against ROS under saline conditions (Mittova et al., 2004; Najami et al., 2008). In the present experiments, the activities of certain antioxidant enzymes, namely GR, catalase and APX, were significantly higher in salt-acclimated plants, contributing to the reduced degradation of chlorophyll molecules.

Gene expression studies showed no significant changes in SOS1 in wheat leaves either after salt acclimation or when exposed to a high salt concentration. In Arabidopsis the SOS1 gene is most strongly expressed in epidermal cells at the root tip and in parenchyma cells surrounding the vascular tissues. Under severe salt stress SOS1 limited the accumulation of $\mathrm{Na}^{+}$in Arabidopsis (Shi et al., 2002), and it also prevented $\mathrm{Na}^{+}$from reaching the photosynthetic tissues in the stems of tomato (Olias et al., 2009a,b). However, in the present experiments salt acclimation did not reduce the Na content in the leaves. In contrast to SOS1, SOS 2 was highly induced in the leaves by extreme salinity; however, there was no difference 
in expression level between acclimated and non-acclimated plants. This suggests that neither the SOS1 nor the SOS2 gene plays a decisive role in salt acclimation processes. Similar results were obtained for the $\mathrm{Na}^{+} / \mathrm{H}^{+}$antiporter gene $\mathrm{NHX}$. This is in accordance with earlier findings that $N H X$ s could not be used to predict salinity stress tolerance in barley plants (Adem et al., 2014). In contrast to these genes, the expression level of another stress-related gene, WALI6 showed a marked increase not only in salt-stressed, but also in salt-acclimated plants. It has been suggested that this gene encodes a protease inhibitor and can be induced by aluminium, especially in the roots (Richards et al., 1994; Drummond et al., 2001). Recently, the elevated expression of WALI6 was observed in the leaves after wheat seedlings were exposed to $\mathrm{H}_{2} \mathrm{O}_{2}$ (Ge et al., 2013). As aluminium toxicity and tolerance are also associated with the accumulation of ROS and oxidative stress tolerance (Darko et al., 2004), a connection between the expression of WALI6 and the oxidative stress response seems to be a possibility. It is likely that it plays a role in the salt stress response and acclimation, and may contribute to improved salt tolerance. However, the direct function of this gene has not yet been described in relation to salt stress and salt acclimation processes, and the direct function of this gene and how it contributes to improved salt tolerance are still unknown.

\section{Conclusions}

In conclusion, the irrigation of wheat plants with a low concentration of $\mathrm{NaCl}$ successfully led to the acclimation of the plants. This was manifested as reduced chlorotic symptoms and less impaired photosynthetic processes when the plants were exposed to a subsequent highdose salt treatment. Several protective mechanisms are induced by salt stress; however, the salt acclimation processes may be different to those induced by severe salinity. The present results suggest that in wheat leaves the increase in the osmotic potential, the increased activity 
of certain ROS scavenging enzymes and the induced expression of certain stress-related genes may play an important role in salt acclimation processes.

\section{Acknowledgements}

This work was financed by grant No. K104963 from the Hungarian Scientific Research Fund.

\section{References}

Ádám, A.L., Bestwick, C.S., Barna, B., Mansfield, J.W., 1995. Enzymes regulating the accumulation of active oxygen species during the hypersensitive reaction of bean to Pseudomonas syringae pv. phaseolicola. Planta 197, 240-249.

Adem, G.D., Roy, S.J., Zhou, M., Bowman, J.P., Shabala, S., 2014. Evaluating contribution of ionic, osmotic and oxidative stress components towards salinity tolerance in barley. BMC Plant Biol. 14, 113

Aharon, G.S., Apse, M.P., Duan, S.L., Hua, X.J., Blumwald, E., 2003. Characterization of a family of vacuolar $\mathrm{Na}^{+} / \mathrm{H}^{+}$antiporters in Arabidopsis thaliana. Plant and Soil 253: 245256.

Amzallag, G.N., Lerner, H.R., Poljakoff-Mayber, A., 1990. Induction of increased salt tolerance in Sorghum bicolor by $\mathrm{NaCl}$ pretreatment. J. Exp. Bot. 41: 29-34.

Anton, A., Rékási, M., Uzinger, N., Széplábi, G., Makó, A., 2012. Modelling the potential effects of the Hungarian red mud disaster on soil properties. Water Air Soil Pollut. 223, $5175-5188$ 
Bajji, M,, Lutts, S., Kinet, J., 2001. Water deficit effects on solute contribution to osmotic adjustment as a function of leaf ageing in three durum wheat (Triticum durum Desf.) cultivars performing differently in arid conditions. Plant Sci. 160, 669-681.

Bassil, E., Tajima, H., Liang, Y.C., Ohto, M.A., Ushijima, K., Nakano, R., Esumi, T., Coku, A., Belmonte, M., Blumwald, E., 2011. The Arabidopsis $\mathrm{Na}^{+} / \mathrm{H}^{+}$antiporters NHX1 and NHX2 control vacuolar $\mathrm{pH}$ and $\mathrm{K}^{+}$homeostasis to regulate growth, flower development, and reproduction. Plant Cell 23, 3482-3497.

Bassil, E., Blumwald, E. 2014. The ins and outs of intracellular ion homeostasis: NHX-type cation/ $\mathrm{H}^{+}$transporters. Curr. Op. Plant Biol. 22: 1-6

Barragan, V., Leidi, E.O., Andres, Z., Rubio, L., De Luca, A., Fernandez, J.A., Cubero, B., Pardo, J.M. 2012. Ion exchangers NHX1 and NHX2 mediate active potassium uptake into vacuoles to regulate cell turgor and stomatal function in Arabidopsis. Plant Cell 24, $1127-1142$.

Darko, É., Ambrus, H., Stefanovits-Bányai, É., Fodor, J., Bakos, F., Barnabás, B., 2004. Aluminium toxicity, Al tolerance and oxidative stress in an Al-sensitive wheat genotype and in Al-tolerant lines developed by in vitro microspore selection. Plant Sci. 166, 583591.

Darko, É., Janda, T., Majláth, I., Szopko, D., Dulai, S., Molnár, I., Türkösi, E., Molnár-Láng, M., 2015. Salt stress response of wheat-barley addition lines carrying chromosomes from the winter barley "Manas". Euphytica 203, 491-504.

Do, P.T., Drechsel, O., Heyer, A.G., Hincha, D.K., Zuther, E., 2014. Changes in free polyamine levels, expression of polyamine biosynthesis genes, and performance of rice cultivars under salt stress: a comparison with responses to drought. Front. Plant Sci. 5: 182. 
Drummond, R.D., Guimarães, C. T., Felix, J., Ninamango-Cárdenas, F.E., Carneiro, N.P., Paiva, E., Menossi, M., 2001. Prospecting sugarcane genes involved in aluminum tolerance. Gen. Mol. Biol. 24, 221-230.

Ge, P., Hao, P., Cao, M., Guo, G., Lv, D., Subburaj, S., Li, X., Yan, X., Xiao, J., Ma, W., Yan, Y., 2013. iTRAQ-based quantitative proteomic analysis reveals new metabolic pathways of wheat seedling growth under hydrogen peroxide stress. Proteomics 13, 3046-3058.

Hasegawa, P.M., Bressan, R.A., Zhu, J.K., Bohnert, H.J., 2000. Plant cellular and molecular responses to high salinity. Annu. Rev. Plant Physiol. Plant Mol. Biol. 51, 463-99.

Hossain, H., Rahman, M.A., Alam, M.S., Singh, R.K., 2015. Mapping of quantitative trait loci associated with reproductive-stage salt tolerance in rice. J. Agron. Crop Sci. 201, $17-31$.

Janda, T., Szalai, G., Tari, I., Páldi, E., 1999. Hydroponic treatment with salicylic acid decreases the effects of chilling injury in maize (Zea mays L.) plants. Planta 208, 175180.

Janda, T, Majláth, I, Szalai, G., 2014. Interaction of temperature and light in the development of freezing tolerance in plants. J. Plant Growth Regul. 33, 460-469.

Kiani-Pouya, A., Rasouli, F., 1994. The potential of leaf chlorophyll content to screen breadwheat genotypes in saline conditions. Photosynthetica 52, 288-300.

Klughammer, C., Schreiber, U., 2008. Complementary PS II quantum yields calculated from simple fluorescence parameters measured by PAM fluorometry and the saturation pulse method. PAM Application Notes 1, 27-35.

Kranner, I., Seal, C.E., 2013. Salt stress, signalling and redox control in seeds. Func. Plant. Biol. 40, 848-859. 
Lichtenthaler, H., 1987. Chlorophylls and carotenoids: Pigments of photosynthetic biomembranes. Methods in Enzymol. 148, 350-382.

Makino, A., Miyake, C., Yokota, A., 2002. Physiological functions of the water-water cycle (Mehler reaction) and the cyclic electron flow around PSI in rice leaves. Plant Cell Physiol. 43, 1017-1026.

Minocha, R., Majumdar, R., Minocha, S.C., 2014. Polyamines and abiotic stress in plants: a complex relationship, Front. Plant Sci. 5, 175.

Mittova, V., Guy, M., Tal, M., Volokita, M., 2004. Salinity up-regulates the antioxidative system in root mitochondria and peroxisomes of the wild salt-tolerant tomato species Lycopersicon pennellii. J. Exp. Bot. 55, 1105-1113.

Najami, N., Janda, T., Barriah, W., Kayam, G., Tal, M., Guy, M., Volokita, M., 2008. Ascorbate peroxidase gene family in tomato: its identification and characterization. Mol. Genet. Genom. 279, 171-182.

Németh, M., Janda, T., Horváth, E., Páldi, E., Szalai, G., 2002. Exogenous salicylic acid increases polyamine content but may decrease drought tolerance in maize. Plant Sci. $162,569-574$.

Olías, R., Eljakaoui, Z., Pardo, J.M., Belver A., 2009a. The $\mathrm{Na}^{+} / \mathrm{H}^{+}$exchanger SOS1 controls extrusion and distribution of $\mathrm{Na}^{+}$in tomato plants under salinity conditions. Plant Signal Behav. 4, 973-976.

Olías. R., Eljakaoui, Z., Li, J., De Morales, P.A., Marín-Manzano, M.C., Pardo, J.M., Belver, A., 2009b. The plasma membrane $\mathrm{Na}^{+} / \mathrm{H}^{+}$antiporter SOS1 is essential for salt tolerance in tomato and affects the partitioning of $\mathrm{Na}^{+}$between plant organs. Plant Cell Environ. $32,904-916$.

Pál, M., Kovács, V., Szalai, G., Soós, V., Ma, X., Liu, H., Mei, H., Janda, T., 2014. Salicylic acid and abiotic stress responses in rice. J. Agron. Crop Sci. 200, 1-11. 
Pál, M., Szalai, G., Janda, T., 2015. Speculation: Polyamines are important in abiotic stress signalling. Plant Sci. 237, 16-23.

Pandolfi, C., Mancuso, S., Shabala, S., 2012. Physiology of acclimation to salinity stress in pea (Pisum sativum). Env. Exp. Bot. 84, 44-51.

Parida, A.K., Das, A.B., 2005. Salt tolerance and salinity effects on plants: a review. Ecotox. Environ. Safety 60, 324-349.

Patade, V.Y., Bhargava, S., Suprasanna, P., 2009. Halopriming imparts tolerance in sensitive sugarcane cultivar to salt and PEG induced drought stress. Agri. Eco. Environ. 134, 2428.

Qiu, Q.S., Guo, Y., Dietrich, M.A., Schumaker, K.S., Zhu, J.K., 2002. Regulation of SOS1, a plasma membrane $\mathrm{Na}^{+} / \mathrm{H}^{+}$exchanger in Arabidopsis thaliana, by SOS2 and SOS3. Proc. Natl. Acad. Sci. USA 99, 8436-8441.

Richards, K.D., Snowden, K.C. Gardner, R.C., 1994. Wali6 and wali7 - genes induced by aluminum in wheat (Triticum aestivum L.) roots. Plant Physiol. 105, 1455-1456.

Saqib, Z.A., Akhtar, J., Saqib, M., Ahmad, R., 2011. Contrasting leaf $\mathrm{Na}^{+}$uptake and transport rates conferred differences in salt tolerance of wheat genotypes. Acta Agric. Scand. Sect. B - Soil Plant Sci. 61, 129-135.

Shi, H.Z., Quintero, F.J., Pardo, J.M., Zhu, J.K., 2002. The putative plasma membrane $\mathrm{Na}^{+} / \mathrm{H}^{+}$ antiporter SOS1 controls long-distance $\mathrm{Na}^{+}$transport in plants. Plant Cell 14, 465-77.

Smith, I.K., Vierheller, T.L., Thorne, C.A., 1988. Assay of glutathione reductase in crude tissue homogenates using 5,5'-dithiobis(2-nitrobenzoic acid). Anal. Biochem. 175, 408413.

Stepien, P., Johnson, G.N., 2009. Contrasting responses of photosynthesis to salt stress in the glycophyte Arabidopsis and the halophyte Thellungiella: Role of the plastid terminal oxidase as an alternative electron sink. Plant Physiol. 149, 1154-1165. 
Tiburcio, A.F., Altabella, T., Bitrián, M., Alcázar, R., 2014. The roles of polyamines during the lifespan of plants: from development to stress. Planta 240, 1-18.

Umezawa, T., Shimizu, K., Kato, M. Ueda, T., 2000. Enhancement of salt tolerance in soybean with $\mathrm{NaCl}$ pretreatment. Physiol. Plant. 110, 59-63.

Xie, Y.J., Xu, S., Han, B., Wu, M.Z., Yuan, X.X., Han, Y., Gu, Q., Xu, D.K., Yang, Q., Shen, W.B., 2011. Evidence of Arabidopsis salt acclimation induced by up regulation of HY1 and the regulatory role of RbohD derived reactive oxygen species synthesis. Plant J. 60, 280-292.

Yokoi, S., Quintero, F.J., Cubero, B., Ruiz, M.T., Bressan, R.A., Hasegawa, P.M., Pardo, J.M., 2002. Differential expression and function of Arabidopsis thaliana NHX $\mathrm{Na}(+) / \mathrm{H}(+)$ antiporters in the salt stress response. Plant J. 30, 529-539. 
Legends to Figures:

Fig. 1. Effects of 5-day salt stress with $500 \mathrm{mM} \mathrm{NaCl}(+500)$ on the chlorophyll content (A) chlorophyll $a / b$ ratio (B) and carotenoid content (C) of control wheat plants and plants acclimated with $25 \mathrm{mM} \mathrm{NaCl}$ (Accl.) in wheat plants. Data represent mean values $\pm \mathrm{SD}, \mathrm{n}=5$. Different letters indicate significant differences at the $\mathrm{P}<0.05$ level.

Fig. 2. Effects of 5-day salt stress with $500 \mathrm{mM} \mathrm{NaCl}(+500)$ on the $\mathrm{Na}$ content in the leaves of control wheat plants and plants acclimated with $25 \mathrm{mM} \mathrm{NaCl}$ (Accl.). Data represent mean values $\pm \mathrm{SD}, \mathrm{n}=3$. Different letters indicate significant differences at the $\mathrm{P}<0.05$ level.

Fig. 3. Effects of 1-day salt stress with $500 \mathrm{mM} \mathrm{NaCl}(+500)$ on the osmotic potential in the leaves of on control wheat plants and plants acclimated with $25 \mathrm{mM} \mathrm{NaCl}$ (Accl.). Data represent mean values $\pm \mathrm{SD}, \mathrm{n}=4$. Different letters indicate significant differences at the $\mathrm{P}<0.05$ level.

Fig. 4. Effects of 1-day salt stress with $500 \mathrm{mM} \mathrm{NaCl}(+500)$ on the free $(\mathrm{A})$ and conjugated (B) polyamine contents in the leaves of control wheat plants and plants acclimated with 25 $\mathrm{mM} \mathrm{NaCl}$ (Accl.). White bars: putrescine (PUT); black bars: spermidine (SPD); dotted bars: spermine $(\mathrm{SPM})$. Data represent mean values $\pm \mathrm{SD}, \mathrm{n}=5$. Different letters indicate significant differences between the same polyamines at the $\mathrm{P}<0.05$ level.

Fig. 5. Effects of 1-day salt stress with $500 \mathrm{mM} \mathrm{NaCl}(+500)$ on the activity of A: glutathione reductase (GR); B: catalase; C: ascorbate peroxidase (APX) and D: guaiacol peroxidase (GPOD) enzymes in the leaves of control wheat plants and plants acclimated with $25 \mathrm{mM} \mathrm{NaCl}$ 
(Accl.). Data represent mean values $\pm \mathrm{SD}, \mathrm{n}=5$. Different letters indicate significant differences at the $\mathrm{P}<0.05$ level.

Fig. 6. Effects of 1-day salt stress with $500 \mathrm{mM} \mathrm{NaCl}(+500)$ on the expression levels of the SOS1 (black bars), SOS2 (white bars), NHX2 (grey bars) and WALI6 genes (dotted bars) in the leaves of control wheat plants and plants acclimated with $25 \mathrm{mM} \mathrm{NaCl}$ (Accl.). Data represent mean values $\pm \mathrm{SD}, \mathrm{n}=3$. Different letters indicate significant differences between the same genes at the $\mathrm{P}<0.05$ level. 
Table 1. Gene-specific PCR primers used in this study.

\begin{tabular}{|c|c|c|c|}
\hline Gene name & & Gene ID (Accession No.)* & Primer sequences (5', to $\left.3^{\prime}\right)$ \\
\hline Ta30797 & gamma & & forward 5'-GCCGTGTCCATGCCAGTG-3' \\
\hline $\begin{array}{l}\text { reference } \\
\text { gene }\end{array}$ & $\begin{array}{l}\text { hydroxybutyrate } \\
\text { dehydrogenase }\end{array}$ & TC279294, TC284282 & reverse 5'-TTAGCCTGAACCACCTGTGC-3' \\
\hline NHX2 & $\begin{array}{l}\mathrm{Na}+/ \mathrm{H}+ \\
\text { antiporter }\end{array}$ & AY040246.2 & $\begin{array}{l}\text { forward 5'-ATTTTGCTCGGGTTGGTTCTGGTT-3' } \\
\text { reverse 5'-GTGCAGGGACTTCGGTGACGC-3' }\end{array}$ \\
\hline SOS1 & $\begin{array}{l}\text { salt overly } \\
\text { sensitive } 1\end{array}$ & KJ563230.1 & $\begin{array}{l}\text { forward 5'-AGAGTACGGGACCAAGCATG-3' } \\
\text { reverse 5'-AGGAGCTCTCGAAGAGGAGG-3' }\end{array}$ \\
\hline SOS2 & $\begin{array}{l}\text { salt overly } \\
\text { sensitive } 2\end{array}$ & JP218831.1 & $\begin{array}{l}\text { forward 5'-GGTTGCTGGTGACTCTCTGG-3' } \\
\text { reverse 5'-AAGGTGTATCCGCGGTAGTG-3' }\end{array}$ \\
\hline WALI6 & $\begin{array}{l}\text { wheat } \\
\text { aluminium } \\
\text { induced } 6\end{array}$ & L28009.1 & $\begin{array}{l}\text { forward 5'-GGACAAGGTGAGAGCTTTGC-3' } \\
\text { reverse 5'-GTTCGCCTGTGAGAGGATTC-3' }\end{array}$ \\
\hline
\end{tabular}


Table 2. Effects of salt acclimation with $25 \mathrm{mM} \mathrm{NaCl}$ on gas exchange parameters, namely net assimilation rate $(\mathrm{Pn})$, intercellular $\mathrm{CO}_{2}$ concentration $\left(\mathrm{C}_{\mathrm{i}}\right)$, stomatal conductivity $\left(\mathrm{g}_{\mathrm{s}}\right)$, transpiration rate (E), and water use efficiency (WUE) determined on the $12^{\text {th }}$ day of the salt acclimation period in wheat plants. Data represent mean values $\pm \mathrm{SD}, \mathrm{n}=5$. $* * *$ : significant differences between acclimated and non-acclimated plants at the $\mathrm{P}<0.001$.

\begin{tabular}{ccc}
\hline & Control & Salt-acclimated \\
\hline $\mathrm{Pn}$ & $7.2 \pm 0.4$ & $6.0 \pm 0.6^{* * *}$ \\
$\left(\mu \mathrm{mol} \mathrm{CO}_{2} \mathrm{~m}^{-2} \mathrm{~s}^{-1}\right)$ & & \\
$\mathrm{C}_{\mathrm{i}}$ & $260 \pm 29$ & $252 \pm 18$ \\
$\left(\mu \mathrm{mol} \mathrm{mol}^{-1}\right)$ & & \\
$\mathrm{g}_{\mathrm{s}}$ & $190 \pm 26$ & $91 \pm 12^{* * *}$ \\
$\left(\mathrm{mmol} \mathrm{H}_{2} \mathrm{O} \mathrm{m}^{-2} \mathrm{~s}^{-1}\right)$ & & \\
$\mathrm{E}$ & $1.46 \pm 0.17$ & $1.17 \pm 0.11^{* * *}$ \\
$\left(\mathrm{mmol} \mathrm{H}_{2} \mathrm{O} \mathrm{m}^{-2} \mathrm{~s}^{-1}\right)$ & & \\
$\mathrm{WUE}_{\left(\mu \mathrm{mol} \mathrm{CO} \mathrm{mmol} \mathrm{H}_{2} \mathrm{O}^{-1}\right)}$ & & \\
\hline
\end{tabular}


Table 3. Chlorophyll a fluorescence induction parameters in salt-acclimated $(25 \mathrm{mM} \mathrm{NaCl}$; Accl.) and non-acclimated control wheat plants and after 5 days of salt stress $(500 \mathrm{mM} \mathrm{NaCl}$; +500 ). Data represent mean values $\pm S D, n=6$. Different letters indicate statistically significant differences at the $\mathrm{P}<0.05$ level.

\begin{tabular}{ccccc}
\hline & Control & Accl. & Control +500 & Accl. +500 \\
\hline $\mathrm{F}_{\mathrm{v}} / \mathrm{F}_{\mathrm{m}}$ & $0.762 \pm 0.015^{\mathrm{ab}}$ & $0.775 \pm 0.011^{\mathrm{a}}$ & $0.645 \pm 0.068^{\mathrm{c}}$ & $0.734 \pm 0.063^{\mathrm{b}}$ \\
$\Phi_{\mathrm{PS} 2}$ & $0.243 \pm 0.031^{\mathrm{a}}$ & $0.277 \pm 0.029^{\mathrm{a}}$ & $0.185 \pm 0.016^{\mathrm{b}}$ & $0.248 \pm 0.053^{\mathrm{a}}$ \\
& & & & \\
$\mathrm{NPQ}$ & $0.576 \pm 0.037^{\mathrm{b}}$ & $0.558 \pm 0.021^{\mathrm{b}}$ & $0.625 \pm 0.022^{\mathrm{a}}$ & $0.571 \pm 0.038^{\mathrm{b}}$ \\
\hline
\end{tabular}

